sought from these key stakeholders, along with others, to gain consensus and build support for the new Coalition. This iterative process resulted in a Coalition mission, goals, values, expected member roles, and priority areas of focus which represented the breadth of key stakeholder concerns and priorities. These foundational principles will be presented in depth. Within fourteen months of project start-up, 25 organisations have joined the NCSH and are actively participating in its Action Groups. This participatory, consensusbuilding approach could hold promise for other coalition-building efforts.

\section{P5.056 MISSION IS POSSIBLE! THE GERMAN STI-SOCIETY (DSTIG) AS A PACEMAKER FOR SEXUAL HEALTH AND STI- RESEARCH IN GERMANY}

doi:10.1136/sextrans-2013-051184.1100

\begin{abstract}
${ }^{1,2} \mathbf{N}$ H Brockmeyer, ${ }^{3} \mathrm{~V}$ Bremer, ${ }^{4} \mathrm{H}$ Langanke. 'German STI-Society (DSTIG), Bochum, Germany; ${ }^{2}$ Clinic for Dermatology, Venerology and Allergology, Ruhr-Universität Bochum, Bochum, Germany; ${ }^{3}$ German STI-Society (DSTIG), Berlin, Germany; ${ }^{4}$ German STI-Society (DSTIG), Cologne, Germany
\end{abstract}

Background For the last 111 years the "German STI Society - Society for the Promotion of Sexual Health" (DSTIG) has been the biggest medical and social society focusing on sexually transmitted infections (STI), which brings clinicians, therapists, people working in the sexual health sector or in STI counselling together. This interdisciplinary approach makes it unique in the German landscape of medical societies.

Through it's history the DSTIG achieved a lot, even though a peak-number of 10,000 members in the 1920s is not reached yet again: The transformation through the years has been from a mainly clinically-pathologically oriented Dermato-Venerological expert group to an open society, which focuses on the whole range of STI-research and sciences, including sexual health.

Organization \& Projects: The members of the DSTIG do work on specific topics in six sections for example in the field of sexual health, medical guidelines, STI-research and/or the development of STI-training material. Amongst other projects and publications, the DSTIG-sections developed prevention standards and indicators to measure sexual health, and treatment guidelines on gonorrhoea. Comprehensive recommendations for counselling, diagnosis and treatment of STI patients are being developed; guidelines for Chlamydia and Syphilis are under progress.

Goals Between 2010-2012 the number of members increased by $51 \%$, which is an obvious indicator that the interdisciplinary way of the DSTIG is the right direction. Taking over responsibility by focusing on the people living at the "edges" of our society like sexworkers, immigrants, homosexuals etc. is one of the goals of the DSTIG. As well the DSTIG is on the way to become an important player in the development of STI-guidelines, and this not only on national level but Europe-wide. Therefore the expertise of physicians from different medical disciplines and the close cooperation between professionals on different levels of the German health system are necessary for success.

\section{P5.057 DO YOU GYT? EVALUATION OF THE FIRST TWO YEARS OF THE UNITED STATES' NATIONAL GET YOURSELF TESTED CAMPAIGN}

doi:10.1136/sextrans-2013-051184.1101

\footnotetext{
'A Friedman, 'M Habel, 'R Kachur, ${ }^{1} \mathrm{~K}$ Brookmeyer, ${ }^{1} \mathrm{M}$ McFarlane, ${ }^{1} \mathrm{M}$ Hogben, ${ }^{2} \mathrm{M}$ Mishel, ${ }^{2} \mathrm{~S}$ Levine, ${ }^{3} \mathrm{~L}$ Vadnai, ${ }^{2} \mathrm{~L}$ Kantor. ${ }^{1}$ US Centers for Disease Control \& Prevention, Atlanta, GA, United States, ${ }^{2}$ Kaiser Family Foundation, Menlo Park, CA, United States, ${ }^{3}$ MTV Networks, New York, NY, United States, ${ }^{4}$ Planned Parenthood Federation of America, New York, NY, United States
}

Background The National Get Yourself Tested (GYT) Campaign was launched in 2009 to promote STD communication and testing among youth ( $\leq 25$ years) through multimedia platforms, on-theground outreach, and linking youth to free/low-cost STD testing. It is a public-private partnership effort between the U.S. Centers for Disease Control and Prevention (CDC), MTV Networks (MTV), the Henry J. Kaiser Family Foundation, and Planned Parenthood Federation of America, among other partners. This effort sought to evaluate campaign exposure and associations with STD testing and communication among youth during the first two years of implementation.

Methods Media metrics tracked campaign-related television, web and social-media programmes in 2009-10; a national mail-panel consumer survey of youth assessed campaign recall and self-reported changes in STD testing and discussions in 2010; and STD patient data from partner health centres ( $n=9$ affiliate health centres) tracked STD testing in April 2008 (pre-campaign), 2009 and 2010.

Results In its first two years, GYT received $>18$ hours of airtime on MTV; its website received $>1.5$ million views, and its testing locator made nearly 145,000 clinic referrals. Awareness of GYT among teenage respondents $(n=766)$ on a national survey was $18.3 \%$, among whom roughly $1 / 5$ reported having talked about STDs/testing with a family member $(17.5 \%)$ or friend $(21.2 \%)$. Among participating affiliates, there was a $71.0 \%$ increase in patients receiving STD testing in April 2010, compared to April 2008 (at a period when chlamydia testing rates nationally rose by $<10 \%$ ). Increases were most notable among young, low income and minority patients.

Conclusion This data offers encouraging evidence that GYT is reaching and mobilising youth most in need of testing. Reported testing increases in GYT-partner health centres were greater than national-level trends which varied minimally from 2008-2010. Efforts are underway to conduct a national evaluation of the campaign.

\section{P5.058 A REVIEW OF THE LANDSCAPE OF MOBILE-PHONE APPLICATIONS FOR INFORMATION, EDUCATION, DIAGNOSIS, CARE AND SELF-MANAGEMENT OF SEXUALLY TRANSMITTED INFECTIONS (STIS)}

doi:10.1136/sextrans-2013-051184.1102

'V Gkatzidou, ${ }^{1} \mathrm{~K}$ Hone, ${ }^{2} \mathrm{C}$ S Estcourt, ${ }^{3} \mathrm{~S}$ T Sadiq, ${ }^{4} \mathrm{P}$ Sonnenberg. ${ }^{1}$ Brunel University, Uxbridge, UK; ${ }^{2}$ Queen Mary University of London, London, UK; ${ }^{3} S t$. George's University of London, London, UK; ${ }^{4}$ University College London, London, UK

Background Mobile phone applications (apps), which offer a paradigm shift in healthcare, have potential to transform sexually transmitted infection (STI) prevention and management. Currently, few sexual health related apps exist for young people. We reviewed existing sexual health mobile apps to inform the design of apps that could be used in eSTI2: STI self-testing, diagnosis, and self-management linked to internet-based clinical management and support.

Methods Major online app stores for sexual health-related mobile apps were searched, excluding apps without STI-related content, intended exclusively for health care professionals or those not available in English. Eligible apps were downloaded and assessed for user ratings, download rates, interactivity as well as examined for salient content features.

Results Of 1504 matches from the initial search, 40 unique individual apps met the selection criteria (10 for iPhone, 14 for Android, three for Blackberry, three for Windows, 10 multi platform). The three most prevalent features of eligible apps were sexual health and STI awareness information (60\%), testing information (30\%), and risk calculator features (30\%). 11 of the eligible apps (27\%) featured an interactive component and 8 included information for a range of sexual orientations. Sexual health apps were infrequently downloaded (median 100-500 downloads); not highly rated (average 